\title{
SOBRE ELS ORÍGENS DEL CONSOLAT DE MAR DE BARCELONA EL 1279 I SOBRE ELS CONNSOLS D'ULTRAMAR A BORD DE VAIXELLS. UN EXEMPLE DE 1281
}

\author{
Maria Teresa Ferrer i Mallol \\ Institució Milà i Fontanals (CSIC) Barcelona
}

\begin{abstract}
SUMARI
1. El Consolat de Mar de Barcelona.- 2. El Consolat d'Ultramar.- Apèndix documental.
\end{abstract}

\section{El Consolat de Mar de Barcelona}

El barri de Ribera, ubicat prop de la platja a l'anomenat pla d'en Llull i on s'edificà Santa Maria del Mar, s'havia constituiit com a nucli diferenciat dins de la ciutat de Barcelona des del començament del segle XIII. Es distingia per la seva dedicació al comerç marítim i a totes les activitats relacionades amb el mar. Pel setembre de 1243, Jaume I havia reconegut la seva personalitat urbanística i n'havia delimitat el solar: des de les Drassanes fins a la casa de Bernat Olzet $i$ des del mar fins a les construccions de pedra de la ciutat. Els mercaders i homes de mar que hi habitaven també van obtenir privilegis que afavorien el desenvolupament de llurs activitats i, el 7 de gener de 1258, van aconseguir el reconeixement d'una personalitat administrativa: la universitat dels prohoms de Ribera. Amb aquest privilegi Jaume I els concedí la facultat d'elegir un prohom que s'ocupés de protegir els interessos de la Ribera, defensar-la contra cristians $i$ sarraïns, organitzar armaments, aplegar diners per a portar a terme aquests objectius i fer ordinacions per a la mateixa Ribera. La concessió fou feta per un any prorrogable a beneplàcit del rei $^{1}$.

${ }^{1}$ J. M. FONT I RIUS, La universidad de probombres de Ribera de Barcelona y sus ordenanzas martitimas (1258), a Estudis sobre els drets $i$ institucions locals en la Catalunya medieval, Col-lectànea de treballs del Prof. Dr. Josep $\mathbf{M}^{2}$ Font i Rius amb motiu de la seva jubilació acadèmica, 
Tal com ho ha destacat el Prof. J. M. Font i Rius, els habitants de la Ribera es van afanyar a exercir les facultats que els atorgava el privilegi: van elegir un prohom en cap, Jaume Gruny, i van redactar unes ordinacions marítimes que foren aprovades pel rei el 26 d'agost de $1258^{2}$. Diversos autors han considerat aquestes ordinacions com el precedent del Consolat de $\mathrm{Mar}^{3}$.

La falta de notícies sobre la corporació dels prohoms de Ribera després del 1258 havia fet suposar que havia desaparegut i que els ciutadans de classe superior havien guanyat el predomini del govern de la ciutat a costa de l'autonomia de la classe mercantil i marítima ${ }^{4}$. Justament aquest mateix any 1258 el rei Jaume I havia procedit també a reorganitzar el municipi de Barcelona amb l'establiment d'un òrgan de govern format per vuit consellers $i$ assessorat per dos-cents prohoms, que posteriorment es van convertir en cent ${ }^{5}$, el qual procuraria amb el temps absorbir algunes de les competències concedides als prohoms de Ribera. Això és cert, com veurem, només fins a cert punt perquè el municipi va aconseguir finalment controlar els consolats d'Ultramar, per exemple, que les ordinacions de Ribera del 1258 havien confiat als prohoms de la Ribera, però la corporació de la Ribera no va desaparèixer sinó que es va mantenir i transformar.

Ja el mateix Prof. Font i Rius havia assenyalat que l'any 1274, quan Jaume I fou requerit pels prohoms de Barcelona perquè aclarís quines eren les vitualles compreses dins la prohibició pontifícia d'exportació a països sarraïns, va manifestar que quedaven excloses de la prohibició les provisions necessàries per a la tripulació, mercaders i passatgers de la nau que anava a

Barcelona, Edicions Universitat de Barcelona, 1985, pp. 690-691. Cf. el privilegi que legitimava l'associació dels prohoms de Ribera a Llibre del Consolat de Mar, vol. III. 2

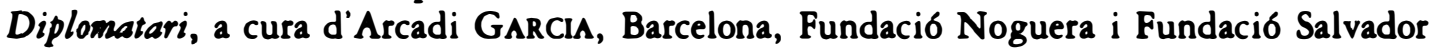
Vives i Casajuana, 1984, doc. 1, pp. 9-10 i l'estudi ibidem, III. 1. Estudi Jurídic, pp. 73-75

2 A. DE CAPMANY, Memorias históricas sobre la marina, comercio y artes de la antigua ciudad de Barcelona,reed. anotada a cura d'E. Giralt y RAventós i C. BATlle y Gallart, Barcelona, Cámara Oficial de Comercio y Navegación, 1961, doc. 14 (II, 10 antiga ed.) i Consolat de Mar, a cura de F. VAlls I TAVERner, Barcelona, Ed Barcino, 1931, II, 119-134 (Els Nostres Clàssics, 37).

${ }^{3}$ J. M. FONT I RIUS, La universidad de probombres de Ribera de Barcelona y sus ordenanzas martitimas (1258), a Estudis sobre els drets $i$ institucions locals en la Catalunya medieval, pp. $692-$ 707. Cf. també Llibre del Consolat de Mar, vol. III. 1. Estudi Jurídic, a cura d'Arcadi GARCIA, pp. 73-77.

4 C. Batlle i Gallart, La crisis social y económica de Barcelona, I, pp. 71 i ss. J. M. FONT I RIUS, La universidad de probombres de Ribera de Barcelona y sus ordenanzas marítimas, pp. 691 i 707-711. Cf. també Llibre del Consolat de Mar, vol. III. 1. Estudi Juridic, a cura d'Arcadi GarCIA, pp. 74-77.

s J. M. FONT I RIUS, La universidad de probombres de Ribera de Barcelona y sus ordenanzas marítimas (1258), p.691. 
terra d'infidels i va determinar que dos prohoms de la Ribera, escollits pels peticionaris, s'encarreguessin de concretar quines provisions quedaven autoritzades; aquests prohoms haurien de determinar igualment quines eren les armes $i$ els elements nàutics necessaris per a la defensa i reparació del vaixell, ja que havien quedat compresos igualment en la prohibició papal de comerç amb els sarraïns ${ }^{6}$. Carme Batlle també trobà mencionat el consell de prohoms de Ribera en actuacions urbanístiques en aquest barri, l'any $1278^{7}$.

Aquesta corporació dels prohoms de Ribera, d'activitats poc conegudes des del 1259, es va transformar el 1279 en el Consolat de Mar, amb una estructura més similar a la que quedà consolidada posteriorment. El privilegi de creació del nou òrgan representatiu dels mercaders i homes de mar fou atorgat per Pere el Gran el 19 de juny de 1279. En aquesta ocasió concedí a tots els mercaders de Barcelona la facultat d'elegir-ne dos entre ells perquè procuressin tot el que fos necessari per al bé comú de tots plegats i de la mercaderia. La concessió no havia de significar una disminució dels drets reials i havia de durar de manera indeterminada, subjecta al beneplàcit del monarca. Com podem veure, la concessió és força inconcreta en les atribucions exactes dels mercaders elegits com a caps, que encara no són denominats cònsols; però això pot ésser degut a l'existència de l'antecedent de la corporació dels prohoms de Ribera, que dibuixava un camp d'actuació conegut per tothom. Les novetats més importants són que el consolat naixent es consolida amb una comissió executiva de dos prohoms i que els mercaders de tota la ciutat, $\mathrm{i}$ no pas únicament els homes de mar del barri de Ribera, són els electors dels dos caps de la mercaderia. La tradició de la corporació anterior és patent, però, en la seva actuació posterior, com ho veurem.

El privilegi de Pere el Gran era prou conegut, ja que va ésser publicat per Capmany, però no ha estat inclòs en els estudis recents sobre el Consolat de Mar i se'n desconeixia la connexió amb l'organització dels prohoms de Ribera. Ara aquesta connexió resulta evident en el nomenament d'un cònsol per a Constantinoble efectuat pels dos prohoms escollits en virtut de la concessió reial. El nomenament de cònsol fou expedit el 26 d'agost de 1281 i conté el privilegi de Pere el Gran i, a més, unes ordinacions en català sobre el consolat en vaixells, molt similar a la disposició sobre aquesta matèria continguda a les ordinacions dels prohoms de Ribera de $1258^{8}$; així doncs,

${ }^{6}$ J. M. FONT I RIUS, La universidad de probombres de Ribera de Barcelona y sus ordenanzas marítimas (1258), pp. 709-710.

7 C. BATLE I GAllaRT, Els proboms de la Ribera de Barcelona i llurs atribucions en matèria urbanistica (segona meitat del segle XIII), a El Pla de Barcelona $i$ la seva bistoria, Barcelona, 1984 , p. 160.

8 A. DE CAPMANY, Memorias bistóricas sobre la marina, comercio y artes de la antigua ciudad de Barcelona, I, p. 339 i II, doc. 28 (II, 248 antiga ed.) i Apèndix. 
els dos prohoms exercien la concessió atorgada a aquests, pel que fa al consolat a Ultramar i, per tant, se'n consideraven successors.

Els dos caps dels mercaders eren, l'any 1281, Bartomeu Romeu i Bonanat Barraler, i són els que apareixen en el document que publiquem en Apèndix. Lany 1282, una sentència relativa a la lleuda del port de Blanes esmenta com a «procuratores seu consules universitatis civitatis Barchinone super facto maris" Bartomeu Romeu i Bonanat Borraller, nom que cal identificar amb el Bonanat Barraler del nostre document, i Berenguer Baster i Pere Gallifa ${ }^{9}$. La presència de quatre procuradors o cònsols pot explicar-se per la presència dels dos cònsols del 1281 i els dos del 1282, la qual cosa ens posaria davant d'una pràctica de renovació anual, com fou costum posteriorment.

No té res d'estrany, doncs, que la concessió del consolat de mar de València del 1283 es referís expressament al de Barcelona, que ja existia amb dos cònsols des del 1279, tal com ho acabem de dir.

Tenim ara la data de naixement del consolat de Barcelona en la seva forma definitiva, l'any 1279, però ens falten nous documents que ens aclareixin com els cònsols van passar de l'elecció directa de l'estament mercantil a l'elecció dels consellers de la ciutat, procediment que funcionava regularment al començament del segle XIV ${ }^{10}$.

\section{El Consolat d'Ultramar}

El desenvolupament del comerç marítim català, i molt concretament del barceloní, havia determinat la presència de mercaders i mariners catalans a països diversos i llunyans: al Magreb, a Egipte, a Palestina, a l'Imperi Bizantí i, naturalment, als estats europeus.

Aviat hom veié la conveniència de poder comptar a les escales de les rutes comercials amb persones que defensessin els interessos dels mercaders catalans prop de les autoritats locals, que solucionessin els conflictes entre catalans $i$ que els donessin suport en qualsevol contingència, tal com ho feien altres nacions que havien començat l'expansió comercial abans que els. catalans.

Segurament els primers consolats catalans estables a l'estranger foren el de Tunis i el de Bugia i en general del nord d'Africa, que fou també un dels

9 A. DE CAPMuNY, Memorias históricas sobre la marina, comercio y artes de la antigua ciudad de Barcelona, doc. 32 (II, 19 antiga ed.) Llibre del Consolat de Mar, vol. III. 1. Estudi Juridic, a cura d'Arcadi GARCIA, p. 77.

${ }^{10}$ Llibre del Consolat de Mar, vol. III. 1. Estudi Jurídic, a cura d'Arcadi GARCin, p. 78. 
primers àmbits de l'incipient comerç català. L'any 1253 ja hi havia en ple funcionament un alfondec $\mathrm{i}$ un cònsol a Tunis que depenien del rei ${ }^{11}$.

El consolat estable d'Alexandria també figura entre els més antics. L'any 1262 Jaume I autoritzà Ramon de Conques, un burgès de Montpeller, que hi havia estat enviat com a ambaixador, per a constituir-hi consolat $\mathrm{i}$ alfondec, en nom del rei, si ho permetia el sultà de Babilònia. El permís degué ésser atorgat perquè el 1264 Guillem de Montcada, ciutadà de Barcelona, en fou cònsol. El rei establí que havia d'exercir la jurisdicció sobre tots els seus súbdits, inclosos els montpellerins ${ }^{12}$.

A mitjan segle XIII aquests primers cònsols estables coexistiren amb un altre tipus de consolat, el cònsol que anava a la nau amb els mercaders $\mathrm{i}$ que, com aquests, romania un quant temps a l'escala final.

Aquesta mena de consolat itinerant fou regulat per primera vegada per les Ordinacions de Ribera de Barcelona del 1258, a les quals ens hem referit abans. Les ordinacions disposaren que, abans de salpar de Barcelona, els homes de qualsevol vaixell, tant tripulants com mercaders, n'haurien d'escollir dos entre ells, els quals tindrien autoritat sobre la resta durant el viatge, fos a terra de cristians o de sarrains. Els elegits podrien nomenar cinc consellers a les naus o bé només dos als llenys; aquesta elecció calia fer-la quatre o vuit dies abans de la sortida de la nau des de Barcelona, i qualsevol barceloní que trobessin a les terres de destinació hauria d'obeir aquests prohoms, que actuarien per delegació del rei i del consell de prohoms de la Ribera de Barcelona; si els dos prohoms elegits marxaven de! lloc d'Ultramar on la nau havia anat, havien d'elegir-ne uns altres dos, amb el consell dels consellers designats abans de sortir, perquè els substituïssin ${ }^{13}$.

Però els òrgans de govern del municipi de Barcelona, que havien estat reorganitzats pel rei Jaume I aquell mateix any 1258 , procuraren amb el temps absorbir algunes de les competències concedides als prohoms de Ribera, especialment el nomenament dels cònsols d'Ultramar ${ }^{14}$. Aquests intents són clars en els dos privilegis obtinguts pels consellers de Barcelona el 1266 i el 1268.

$"$ Ch. E. DufourcQ, L'Espagne catalane et le Maghrib aux XIIle et XIVe siècles, París, Presses Universitaires de France, 1966, pp.98-101, 103, 106, 112, 115-118, 125-126, 262, 273.

12 A. LOPEZ DE MENESES, Los consulados catalanes de Alejandría y Damasco en el reinado de Pedro el Ceremonioso, «Estudios de Edad Media de la Corona de Aragón», VI, docs. 1 i 2, pp. 85-88.

13 A. DE CAPMANY, Memorias históricas sobre la marina, comercio y artes de la antigua ciudad de Barcelona, doc. 14 (II, 10 antiga ed.) i Consolat de Mar, a cura de F. VALLS I TAVERner, Barcelona, Ed Barcino, 1931, II, 134 (Els Nostres Clàssics, 37).

14 J. M. FONT I RIUS, La universidad de probombres de Ribera de Barcelona y sus ordenanzas martítimas (1258), p.691. 
En efecte, el 16 d'agost de 1266 Jaume I concedí als consellers de Barcelona potestat per nomenar cònsols cada any a les naus que naveguessin a Ultramar els quals, un cop arribats al port de destinació, si no hi volien hivernar, podrien nomenar un cònsol que els substituís. Els cònsols tindrien jurisdicció sobre totes les persones dels regnes catalano-aragonesos que naveguessin o residissin a Ultramar (nom que solia designar Síria i Egipte i també l'Imperi Bizantí, bé que aquest era esmentat més aviat amb el nom de Romania) i sobre tots els vaixells i béns que transportessin. Podrien ordenar, obligar, administrar justícia i castigar, tal com ho feien els d'altres nacions. Haurien de jurar el càrrec i regir-lo fins al final del termini fixat pels electors. El càstig dels cònsols, si delinquien, correspondria als consellers de Barcelona ${ }^{15}$.

La concessió que acabem de comentar no significava encara el monopoli de la funció consular per a Barcelona, però a la darreria de l'any 1268 Jaume I amplià el privilegi del $1266 \mathrm{i}$ atorgà potestat als consellers de Barcelona per a escollir cònsols a Ultramar i a Romania i a tot arreu on naveguessin els vaixells barcelonins. Tots els seus súbdits hi haurien d'acudir per a resoldre llurs querelles ${ }^{16}$. Aquesta concessió fou la que realment constituí l'inici de la potestat consular barcelonina i s'inserí posteriorment en els nomenaments que feien els consellers, ja que eren en virtut d'aquest privilegi ${ }^{17}$.

Però a la pràctica, els consellers de Barcelona no aconseguiren pas immediatament anul.lar la vigència de la concessió relativa al consolat itinerant previst a les Ordinacions de Ribera del 1258. Es cert que per ara no hi ha notícies del nomenament de cònsols pels prohoms de Ribera, però n'hi ha un per part dels seus immediats successors, els procuradors o cònsols de la mar.

En efecte, l'any 1281, els cònsols de la mar, Bartomeu Romeu i Bonanat Barraler, als quals ja ens hem referit, nomenaren un cònsol a Constantinoble i Romania dins la tradició establerta a les Ordinacions pels prohoms de Ribera, l'any 1258. La persona escollida fou Pere Ris, un mercader de Barcelona que anava a Constantinoble en la nau de Bonany Llor, $\mathrm{i}$ que sabem que continuava traficant al Llevant encara l'any 1295; juntament amb Joan Cap era llavors propietari de la nau "Sant Francesc», que prengué un canvi a pagar a Alexandria ${ }^{18}$. Segons el nomenament consular

15 A. DE CAPManY, Memorias, doc. 19 (II, 3 antiga ed.).

16 A. DE CAPMuNY, Memorias, doc. 23 (II, 14 antiga ed.).

17 A. LOPEZ DE MENeses, Los consulados de Alejandría y Damasco, pp. 89-90.

18 A.GArCin, M.T. Ferrer, Assegurances $i$ canvis maritims medievals a Barcelona, Barcelona, Institut d'Estudis Catalans, 1983,II, 322, n.1. A la tornada d'aquest viatge, l'any 1296, Pere Ris i Joan Cap, juntament amb Berenguer Cap i Pere Foces, tenien un plet amb Pere Teixeda, que els reclamava uns besants d'or $i$ altres quantitats, en virtut d'un contracte 
del 1281, Pere Ris havia de tenir jurisdicció sobre tots els súbdits del monarca català que es trobessin a Constantinoble i a Romania. El nomenament remetia per als detalls de les facultats atribuïdes al cònsol a les ordinacions dictades pels cònsols o procuradors dels mercaders, que foren copiades en el mateix document. Cal constatar que aquestes ordinacions, seguint la tradició de les dels prohoms de Ribera del 1258, disposen el nomenament de dos cònsols a cada vaixell, mentre que en el cas que comentem només en nomenen un. Els cònsols havien de jurar abans de la partença comportar-se bé i lleialment «a honor del senyor rey» i procurar el bé comú de tots els súbdits del monarca i de la mercaderia. Els eren atribuiides facultats coercitives sobre aquestes persones i els seus béns. Aquestes facultats no podien comptar amb una potestat executiva prou eficaç, havent d'exercir-se a l'estranger, i per això hom preveia solucions per als casos de resistència a l'autoritat del cònsol. Si algú no volia obeir-lo, el cònsol, amb testimonis, n'havia de prendre nota i denunciar-ho als cònsols de la mar a la tornada a Barcelona. Només en el cas que algun mercader malbaratés els béns $i$ les mercaderies que tenia sota la seva responsabilitat $i$ que pertanyien segurament a altres persones, el cònsol podia demanar l'ajut de l'autoritat jurisdiccional local per tal d'emparar i salvar aquests béns. La resta de les ordinacions preveien la precedència en l'autoritat consular dels cònsols embarcats en vaixells catalans que coincidissin en un mateix port. Totes les naus catalanes, encara que portessin altres cònsols a bord, haurien d'obeir el cònsol o els cònsols de la primera nau que hagués arribat a port, fos a Ultramar, a Armènia, a Romania o a Barbaria; els cònsols d'aquestes altres naus haurien d'ajudar els primers; els de la segona nau arribada els podrien substituir quan marxessin i així successivament ${ }^{19}$.

De moment, doncs, l'estament mercantil encara exercia autònomament aquesta parcel.la de poder l'any 1281. Queda per aclarir quan el govern municipal aconseguí eliminar aquesta pràctica, perquè fou el municipi qui guanyà finalment la partida.

que havien signat i que afectava la nau de Pere Ris i de Joan Cap. Primerament, confiaren la solució de les diferències a uns àrbitres, però Pere Teixeda no acceptà llur sentència i recorregué al rei. Jaume II confià llavors la causa al jutge de la cort, Jaume de Bianya, canonge d'Urgell: ACA, C reg. 105, f. 223 r. (1296, novembre, 11).

19 Apèndix. 


\section{APENDIX DOCUMENTAL}

\section{1, agost, 26. Barcelona}

Els cònsols de Barcelona, Bartomeu Romeu i Bonanat Barraler, elegits per autoritat del rei Pere i segons el privilegi del 19 de juny de 1279, que és inclòs, per a vetllar pels interessos dels mercaders de Barcelona, nomenen Pere Ris, mercader de Barcelona, cònsol a Constantinoble $i$ tota Romania. Inclouen les ordinacions que li atorguen poders sobre tots els mercaders catalans $i$ preveuen la seva substitució quan marxi de Romania.

ACB, Diversorum C (d), carpeta 5, pergamí núm. 4037, 34'5×24'5 cms.

Noverint universi quod nos, Bartholomeus Romei et Bonanatus Barralerii, mercatores et cives Barchinone, electi auctoritate illustris domini Petri, Dei gracia regis Aragonum, a mercatoribus civitatis Barchinone super mercaturis fideliter et legaliter tractandis et aministrandis, prout in tenore instrumenti dicti domini regis sigillo eiusdem maiori pendenti sigillato, cuius tenor infra scribitur continetur, de consilio et assensu mercatorum Barchinone, ad honorem predicti domini regis Aragonum et ad comunem utilitatem hominum eiusdem elegimus in consulem apud Costantinopolim et in aliis partibus Romanie, Petrum Ris, mercatorem Barchinone, euntem ad dictas partes in navi Bonayn Lauri et sociorum, ita quod ipse habeat potestatem procurandi et aministrandi in dictis partibus omnia ea que viderit expedire hominibus terre dicti domini regis navigantibus et existentibus apud Constantinopolim et in aliis partibus Romanie predictis, quamdiu ipse consul ibi fuerit iuxta ordinaciones nostras que infra continentur et omnes homines de terra dicti domini regis navigantes et existentes in dictis partibus teneantur dicto consuli obedire. In testimonium autem huius rei presens instrumentum iussimus fieri auctoritate Berengarii Lupeti, notarii publici Barchinone infrascripti.

Datum Barchinone $\mathrm{VII}^{\circ}$ kalendas septembris, anno Domini $\mathrm{M}^{\circ} \mathrm{CC}^{\circ}$ octuagesimo primo.

Tenor autem instrumenti dicti domini regis talis est:

Noverint universi quod nos, Petrus, Dei gracia rex Aragonum, volumus et concedimus universis mercatoribus Barchinone qui officium mercacionis seu negociacionis ibi exercent aut exercuerint quod possint eligere inter se et sibi proponere duos mercatores ex ipsius bonos et legales, qui electi de comuni assensu dictorum mercatorum vel maioris partis eorum procurent, aministrent et faciant omnia que necessaria fuerint ad comunem utilitatem ipsorum omnium et singulorum super mercacionibus suis bene et fideliter et absque diminucione nostro- 
rum iurium procurandis. Hanc autem concessionem facere intendimus quamdiu nobis placuerit, salvo iure nostro in omnibus et ita quod iurisdiccioni nostre perpetue ipsam nullatenus derogetur, mandantes vicario, baiulo et aliis officialibus nostris Barchinone, presentibus et futuris, quod hanc concessionem nostram predictis mercatoribus firmam habeant et observent et faciant observari, prout superius continetur.

Datum Valencie, XIII ${ }^{\circ}$ kalendas iulii, anno Domini $\mathrm{M}^{\circ} \mathrm{CC}{ }^{\circ} \mathrm{LXX}^{\circ}$ nono. Signum (signe) Petri, Dei gracia regis Aragonum.

Testes sunt Guillermus de Castronovo, Amor Dionisii, Blascho Masza, Icardus de Muro et Bernardus de Petratallada.

Sig(signe)num Petri de Sancto Clemente, scriptoris predicti domini regis, qui mandato eius hec scribi fecit et clausit loco, die et anno prefixis.

La tenor, emperò, dels dits ordenamens és aquesta: Ordenen en Bartholomeu Romeu e en Bonanat Barraler a honor del senyor rey d'Aragó e a profit de la mercaderia que en cascuna nau vajen II cònsols e que.ls cònsols que juren que bé e leyalment a honor del senyor rey e a cuminal profit de les sues gents e de lur mercaderia procuren tots aquels qui sien de la senyoria del senyor rey d'Aragó a bé e a profit d'éls e que pusquen destrènyer aquels en persones e en coses si avien fet so que no deguessen o no volien obeir als cònsols e si per aventura alcuns d'aquels no.s volien destrènyer per éls, ordenen que.ls cònsols ab testimonis scriven los noms d'aquels e les malesfetes que fetes ajen e que, con seran en Barcelona, que ho dejen denunciar a éls. Item ordenen que quantes que naus vajen en Oltramar o en Ermínia o en Romania o en Barberia o en altres parts que los dits cònsols qui iran en la primera nau qui primerament là farà port, sien apelats e tenguts per cònsols per totes les altres naus qui aquí vendran mentre aquela primera nau hi serà. E.ls altres cònsols qui en les altres naus iran sien conseladors e ajudadors dels primers II cònsols e ab aquels ensemps tracten lo cuminal profit de les lurs gens. E si per aventura los II primers cònsols se.n venien o avien anar en altres parts, aquels dos cònsols de l'altra nau qui aquí feés port aprés de la primera fossen tenguts per cònsols per totes les altres naus, axí com les primeres. E si tant era que la un dels II cònsols falís, que altre hi fos stablit en loc d'aquel, d'aquels so és a saber de l'altra nau qui aprés fos venguda. E axí ordenen que.s seguescha de la primera nau tro a la derrera. Item ordenen que si negú mercader de Barcelona o d'altre loc de la senyoria del senyor rey comensava, segons lur conexensa, de guastar les coses que él agués portades en los dit viatge que éls per si meteis e ab lur consel e encara ab la senyoria de la terra, si als fer no podien, emparassen e presessen e salvassen totes aqueles coses que poguessen trobar al dit mercader.

Sig(signe)num Berengarii Lupeti, notarii publici Barchinone, qui rogatus a dictis Bartholomeo Romei et Bonanato Barralerio hec scripsit et clausit die et anno quo supra.

\section{RÉSUMÉ}

Le Consolat de Mar de Barcelone trouve ses origines dans l'«Universitat dels 
prohoms de Ribera», corporation créé par Jaume I"e, le 7 janvier 1258. Cette corporation avait la faculté d'élire un "prohom» dont la responsabilité était de protéger les intérêts des navigateurs et des commerçants de ce quartier maritime.

Pere el Gran, le 19 juin 1279, octroie au Conslat de Mar un nouveau privilège, privilège qui lui donne une apparence plus proche de celle qui serait finalement la sienne, en le dotant d'un organe représentatif des commerçants de Barcelone, institution constituée par deux "prohoms", élus parmi eux. L'analogie avec la corporation antérieure est évidente en ce qui se réfere à l'exercice des privilèges concédés aux "prohoms» de Ribera qui, de cette façon, pouvaient nommer consuls dans les bateaux catalans qui partaient pour des pays d'outre-mer et qui avaient la capacité de défendre les intérêts des commerçants catalans auprès des autorités locales, de trouver une solution aux conflits entre catalans, etc..

Dans cet article, on publie et commente la première nomination connue d'un consul à bord d'un bateau catalan, en partance pour Constantinople, en 1281 .

\section{SUMMARY}

The Consolat de Mar of Barcelona finds its origins in the "Universitat dels prohoms de Riberax, a corporation created by Jaume the First, on January $7^{\text {th }}$ 1258. This corporation had to elect a "prohom" who was responsible for the protection of the interests of the navigators and merchants of this seaside suburb.

Pere el Gran, on June $19^{\text {th }} 1279$, granted another privilege to the Consolat de Mar, a privilege that models it much like its definitive shape. It consists in endowing it with a representative institution for Barcelona's merchants; it is composed by two "prohoms", elected among them. The analogy with the former corporation is patent as far as the use of privileges granted to the "prohoms" de Ribera is concerned. They were authorised to appoint as consuls in the Catalan ships that went overseas, where they were allowed to defend Catalan merchants' interests to local authorities, to solve conflicts between Catalan citizens, etc..

In this article, the author transcribes and comments the first known appointment of a consul on a Catalan ship that set sail for Constantinople, in 1281 . 